\title{
Microstructure of autonomous self-healing concrete
}

\author{
Teresa Stryszewska ${ }^{1}$, and Marta Dudek $^{2, *}$ \\ ${ }^{1}$ Cracow University of Technology, Faculty of Civil Engineering, Chair of Construction Engineering \\ and Building Physics, Warszawska St. 24, 31-155 Cracow, Poland \\ ${ }^{2}$ Cracow University of Technology, Faculty of Civil Engineering, Chair of Building Materials \\ Engineering, Warszawska St. 24, 31-155 Cracow, Poland
}

\begin{abstract}
Over the past years, many research projects in the field of construction have been based on the concept of intelligent materials. One example of such materials is self-healing concrete. This material has the ability to repair the damage that occurs, which in concrete materials means filling/closing the cracks formed. This paper describes autonomous concrete that heals itself thanks to modifications with mineral additives. The study used the basic method of evaluating the effectiveness of the healing process, which is visual observation of the material. For this purpose, tests were performed using optical, digital and electron microscopes. In addition to the observations, a chemical analysis of the composition was performed using the EDS detector mounted on the SEM. The findings indicate the ability of filling cracks with accumulating products of reaction with water.
\end{abstract}

\section{Introduction}

Self-healing concretes are a type of intelligent materials. Intelligent materials are also commonly referred to as smart materials or functional materials. These are modern materials of the highest class [1]. They have the ability to react appropriately to an external stimulus. This stimulus causes an expected change in material properties, e.g. a change in force, material structure, control of movements or the ability to generate a signal [2,3]. Currently, a lot of research studies are being conducted on intelligent materials, in various fields of science. This name denotes materials with the ability to change their shape, colour and density, as well as materials with self-healing properties.

Self-healing means a self-repairing capability in order to maintain certain characteristics of a material at an appropriate level. In practice, it means that components of a particular material bring about the repair (healing) of the damage [4]. With regard to cement-based materials, such as e.g. concretes, it is a process as a result of which cracks in the material are filled. This process takes place without external intervention [5]. It can therefore be said that the role of self-healing concretes is to detect; and then spontaneously repair small cracks. Ultimately it resulting in the restoration of the original properties, and thus to increase the

\footnotetext{
*Corresponding author: marta.dudek@pk.edu.pl
} 
durability of the material by inhibiting the destructive effects including in particular crack propagation [6, 7].

Self-healing processes can be divided into two basic groups, i.e. autonomic healing and autogenic healing, as presented in Fig. 1.

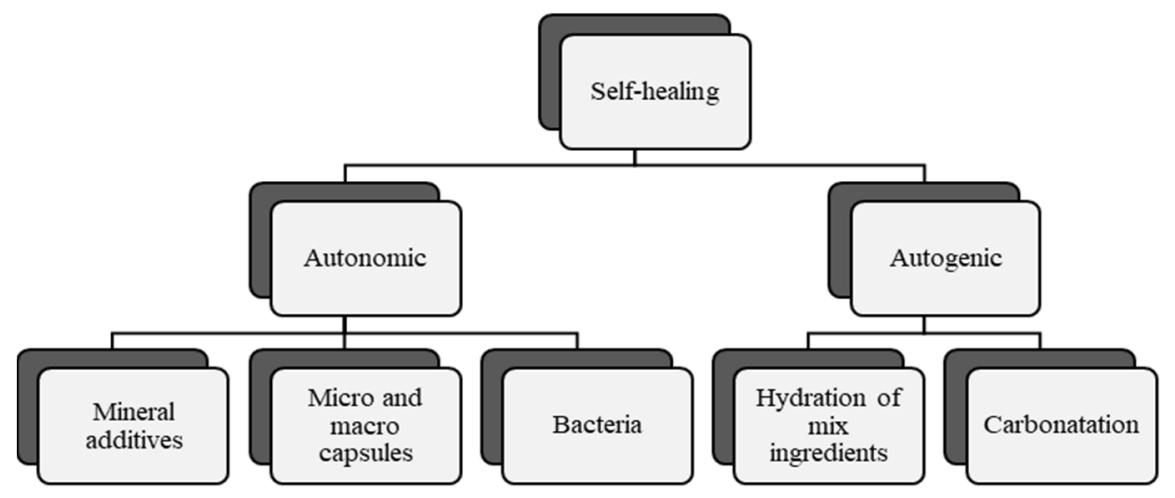

Fig. 1. A chart showing the breakdown of self-healing.

Autonomic healing occurs when additional components have been introduced into the material in order to bring on the self-repairing ability. Autogenic healing, on the other hand, is based on the natural ability of the material, i.e. on the components that are normally present in it. These are mainly reactions with unhydrated cement grains and the carbonisation reaction $[5,8]$.

The autonomic methods include the use of additives in the form of micro- and macrocapsules filled with a healing agent. When the concrete cracks, the capsules break open and their content is released forming a mass that seals the crack. The substances used are usually polymers with two components that form a hard mass when they are mixed or one-component polymers that need moisture to initiate the same process. These are technologically advanced methods $[9,10]$. This group also includes bacteria that can be added directly to the mixture or enclosed in lightweight aggregate or capsules $[11,12]$. Due to the moisture contained in the air/matrix the bacteria proliferate and, as a result of metabolism, excrete calcite which seals the crack [5].

The commonly used solutions include introduction of mineral additives directly into the concrete mix. In contact with moisture they undergo hydration creating new products that seal the cracks. Additives used in this method include fly ash, magnesium oxide, active silica, lime, blast furnace slag and others [13-15]. A schematic of the healing process is presented in Fig. 2.
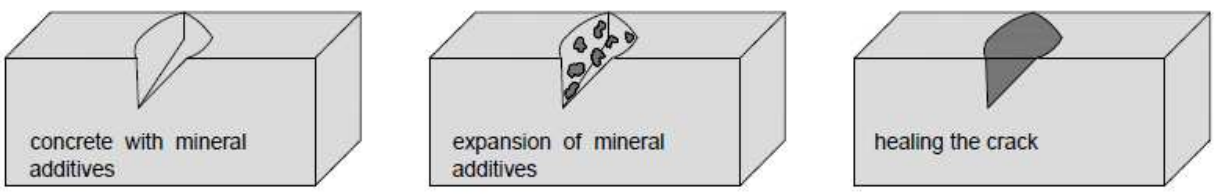

Fig. 2. Crack healing in concretes with mineral additives.

The process of crack filling by means of accumulation/expansion of mineral additives is very similar in its nature to autogenous healing based on hydration of cement grains. The choice of the healing method corresponds to the width of the cracks subjected to this process. Typically, the method of autogenous healing with mineral additives is used to assess the 
efficiency of this process for cracks with a width of approx. 200-300 $\mu \mathrm{m}$ [12]; however, tests were also carried out for larger or smaller crack widths $[6,14,15]$.

The most common additives introduced into concrete include fly ash with pozzolanic properties and blast furnace slag with hydraulic properties. These materials are introduced into the composition mainly as a substitute of Portland cement clinker; at the same time they modify the properties of concrete in terms of strength and durability. Both these mineral additives promote self-healing processes. Cement materials that contain them are characterised by increased self-healing properties as compared with regular concrete [16-19].

Apart from typical additives, there are also other materials that are introduced into the concrete and bring about similar properties, e.g. magnesium oxide. It has expansive properties, and therefore causes cracks to be filled in materials modified with its addition [20, 21]. Apart from the above-mentioned additives, there are many other materials promoting the process of self-healing.

The aim of the research was to assess the self-healing ability of concretes modified with mineral additives. It included the observation of the microstructure of the samples both before and after the treatment process. The significance of the research was influenced by the analysis of the self-healing ability for different crack widths, after a treatment time of six months. Moreover, the disadvantages and difficulties accompanying the selected research procedure were described.

\section{Materials and methods}

The tests were carried out on specimens prepared from concrete with mineral modifying additives (MA) with self-healing properties (MA concrete). Additionally, $35 \mathrm{~mm}$ long steel fibres were used in the concrete in order to facilitate the formation of cracks in the specimens. The additive used to give self-healing properties to concrete was a mixture containing magnesium oxide ( $5 \%$ by weight of cement), slaked lime ( $5 \%$ by weight of cement) and bentonite clay $(2.5 \%$ by weight of cement). These additives replaced a total of $12.5 \%$ of cement in the concrete mix.

Cylindrical specimens were prepared for the study; then the specimens were cut into discs with a diameter of $100 \mathrm{~mm}$ and a height of $50 \mathrm{~mm}$. After 35 days of aging in water, a wedge splitting test was used to pre-crack the specimens, in which a $1.5 \mathrm{~mm}$ wide and deep notch was pre-cut. The desired crack width was about $200 \mu \mathrm{m}$. The pre-cracking was performed using a Zwick/Roell testing machine with a maximum load of $100 \mathrm{kN}$ and the crack width was controlled using a CMOD sensor mounted on one side of the disc (Fig. 3).
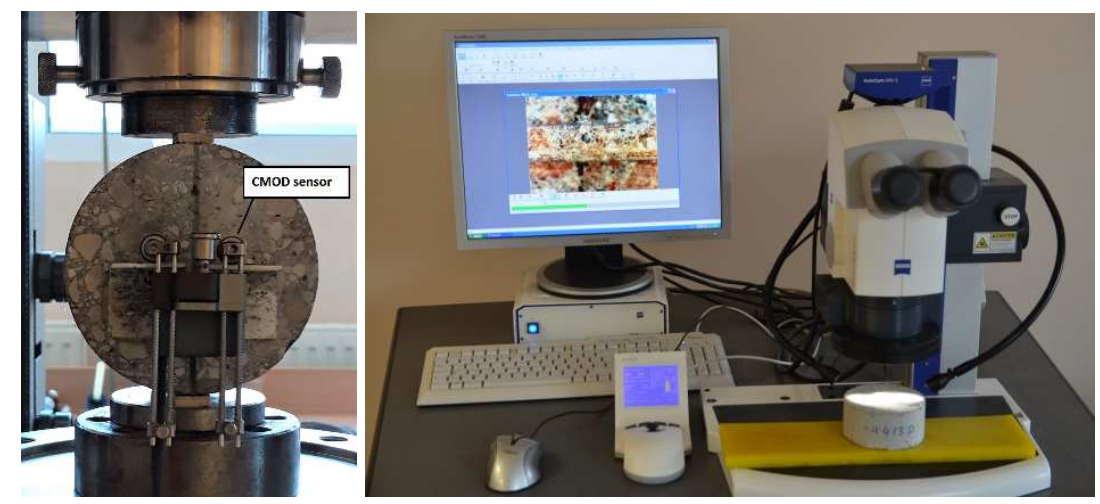

Fig. 3. Sample mounted on a Zwick/Roell Z100 testing machine with a CMOD sensor mounted. Next to it, a crack measuring station with an optical microscope. 
Immediately after the pre-cracking step, the widths of the cracks were measured using a ZEISS Discovery V20 optical microscope. The pre-cracked specimens were then submerged in water again to facilitate the process of self-healing. After 6 months of exposure to water, the cracks and products formed in them were observed. The width and degree of filling were evaluated by observing the cracks. In addition, the specimens were observed under the Keyence VHX-7000 digital microscope and Zeiss EVO-MA 10 scanning microscope equipped with SE, VPSE and BSD detectors. A chemical elemental analysis of the resultant products filling the cracks was also performed using the EDS Bruker XFLASH 6/30 detector.

\section{Results and discussion}

\subsection{Observation in optical, digital and scanning microscope}

Due to the rapidity of the process of destruction of the discs and their heterogeneity at different points, caused by the presence of dispersed reinforcement, strongly diversified crack widths in the range $100 \div 500 \mu \mathrm{m}$ were obtained. Moreover, during the pre-cracking process some specimens were destroyed or the crack width exceeded $500 \mu \mathrm{m}$. Those specimens were discarded from further testing. The pre-cracked specimens used in the study were divided into three groups depending on the crack width, i.e. up to $200 \mu \mathrm{m}$, up to $300 \mu \mathrm{m}$ and up to approx. $500 \mu \mathrm{m}$. Fig. 4 and Fig. 5 show photos of the specimens immediately after the precracking and after 6 months of exposure to water.
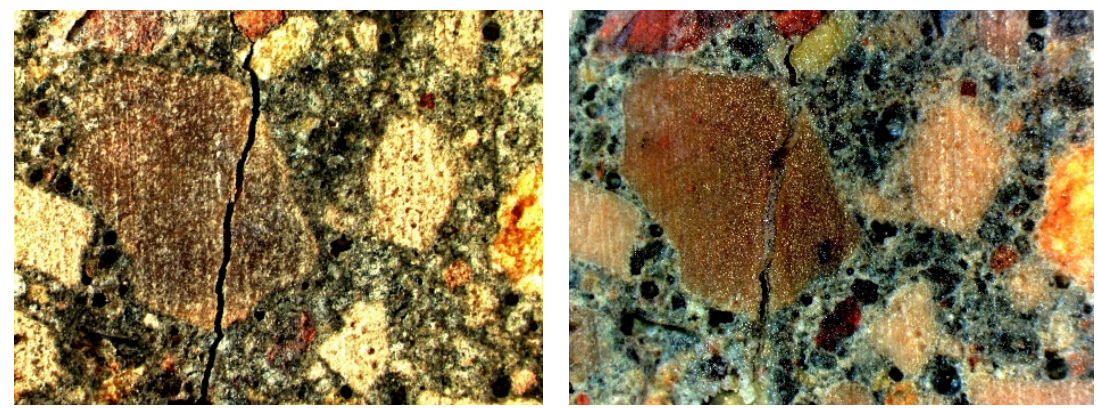

Fig. 4. A photo of a specimen taken under the ZEISS Discovery V20 optical microscope. A crack with a width of $200 \mu \mathrm{m}$ before and after the healing process (left to right)
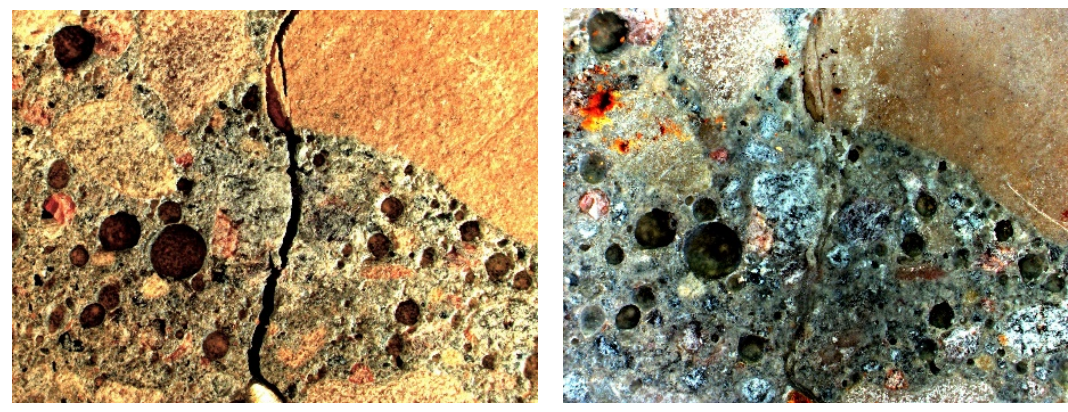

Fig. 5. A photo of a specimen taken under the ZEISS Discovery V20 optical microscope. A crack with a width of $300 \mu \mathrm{m}$ before and after the healing process (left to right)

The observations carried out under a digital microscope confirmed the possibility of cracks healing in the concretes tested as a result of hydration of a mixture of mineral additives $(\mathrm{CaO}$ 
$+\mathrm{MgO}+\mathrm{SiO}_{2}$ ) intentionally introduced into the concrete mixture. It was shown that as a result of the reactions the cracks were filled completely in many places (Fig. 6).
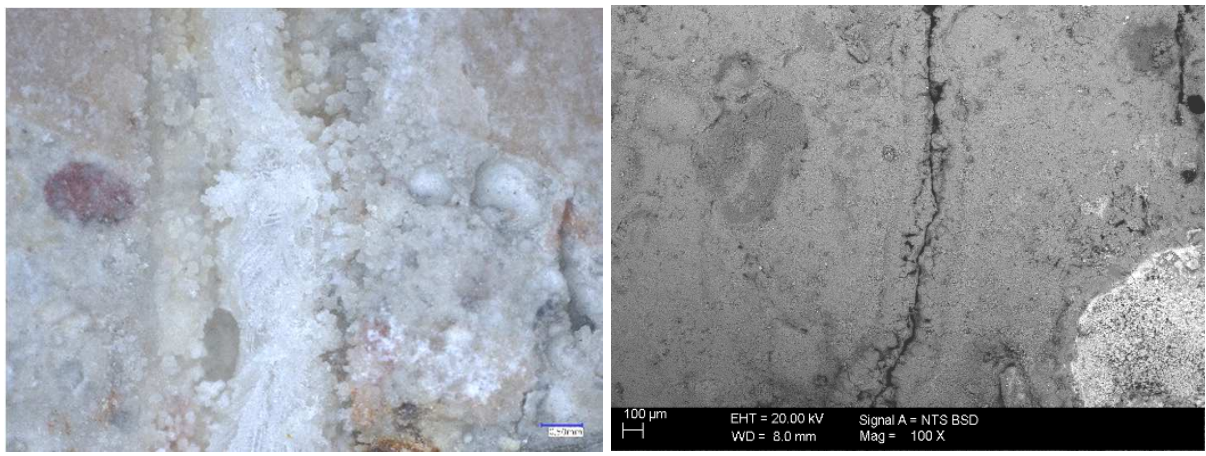

Fig. 6. Microstructure of a specimen with a visible crack completely filled with reaction products (mag. 100x); Keyence VHX-7000 digital microscope. Next is a SEM image of a crack partially filled with reaction products (mag. 100x); scanning microscope EVO-MA 10 Zeiss.

Based on digital microscope observations, it has been confirmed that the effectiveness of crack healing depends on the width of the crack. The best filling of cracks with hydration products was found in specimens with cracks of approx. $200 \mu \mathrm{m}$. However, as shown in the observations, specimens with cracks of approx. $300 \mu \mathrm{m}$ were also characterised by good filling of the cracks. On the other hand, significantly worse healing results were observed in specimens with the largest crack size of approx. $500 \mu \mathrm{m}$. It was also observed that the effectiveness of self-healing depends on the location of the crack. Fig. 4 shows a crack with a width of approx. $200 \mu \mathrm{m}$ running through the aggregate and matrix. In this case the healing of the crack is varied. The crack located in the binder was largely filled with hydration products while the crack in the aggregate was only slightly filled.

The resultant concrete self-healing products are primarily of crystalline nature (Fig. 7). Based on the analysis of the elemental composition made by the EDS method, the presence of calcium carbonate crystals was found, which seems to be the main product filling the cracks. There were also observed products of bentonite hydration, which have well-developed, fibrous gelled spatial structures. An EDS analysis of elemental composition of these structures showed the presence of aluminium in these phases. These products fill the voids between crystals of calcium carbonate (Fig. 8). As Bentonite comes into contact with water it expands, which explains the clear influence of this phase on the process and the efficient crack sealing.
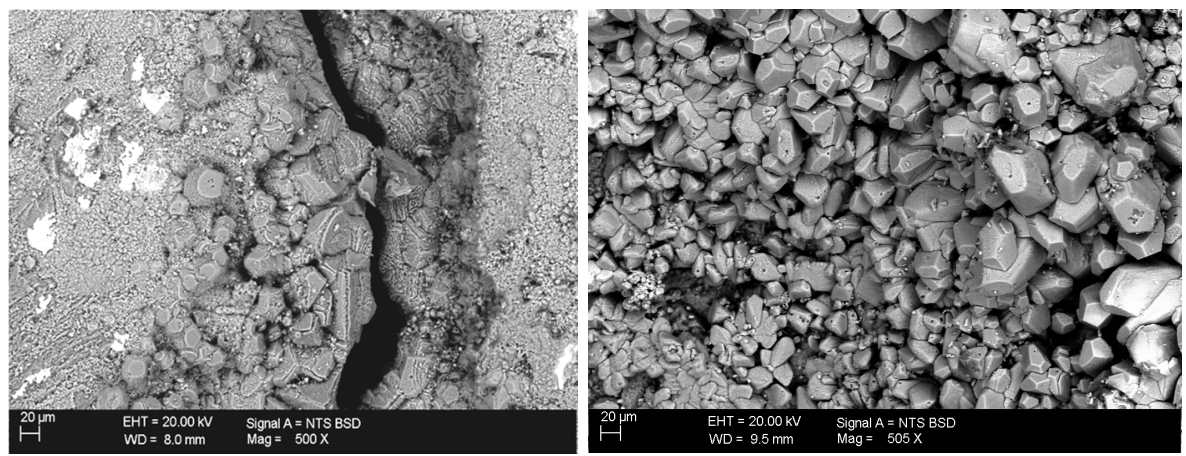

Fig. 7. Microstructure of concrete self-healing products, over 500x. The SEM examination was performed using an EVO-MA 10 Zeiss microscope. 

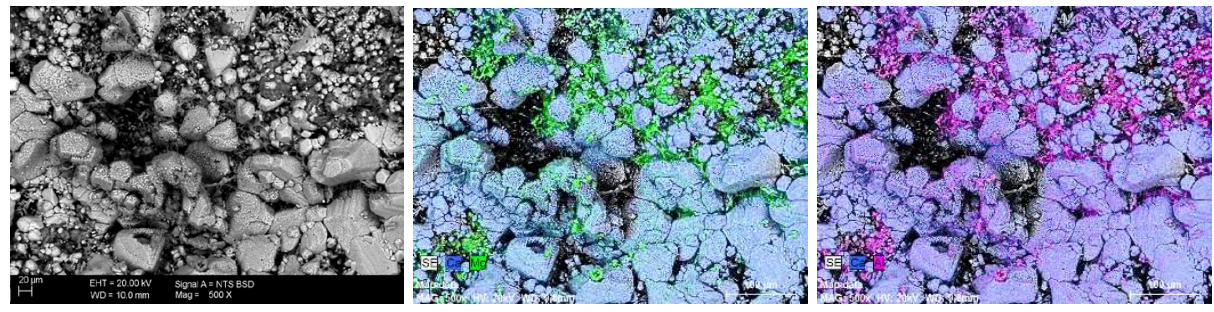

Fig. 8. Microstructure of concrete self-healing products, over 500x, together with an EDS analysis in the form of mapping selected elements: $\mathrm{Ca}$ (blue), $\mathrm{Mg}$ (green) and $\mathrm{Al}$ (pink). The examination was performed using an EVO-MA 10 Zeiss scanning microscope and an EDS Bruker XFLASH 6/30 detector.

The SEM observations also revealed that reaction products formed in the cracks have a different microstructure depending on the distance from the surface. The closer to the surface, the more crystalline and larger the products are. As the distance increases, the calcium carbonate crystals in the crack get finer and the proportion of amorphous, aluminiummagnesium phase increases.

\section{Conclusions}

Observations of the microstructure of self-healing concretes modified with mineral additives (MA) containing magnesium oxide, slaked lime and bentonite clay confirm the possibility of complete healing of cracks in the concrete. The effectiveness of the sealing depends largely on the width of the crack and the location of the crack (aggregate or binder). The best sealing effects, over a set period of time, were achieved for cracks up to $300 \mu \mathrm{m}$. The predominant product filling the cracks is crystalline calcium carbonate, formed by the reaction of calcium hydroxide with atmospheric carbon dioxide. The second crack sealing product observed is aluminium-magnesium gel phase. It is located between the crystals of calcium carbonate and fills the voids, which in turn intensifies the process of crack sealing. Also observed was a differentiation of the healing progress depending on the distance from the concrete surface. The deeper into the material, the finer the crystalline calcium carbonate products are, and there are fewer of them. In the part of the cracks located close to the surface, the amorphous aluminium-magnesium phase is more visible. This shows the heterogeneity of the healing process of concrete with mineral additives at the depth of the crack.

\section{References}

1. J. Strittmattera, P. Gümpela, M. Hiefer, Intelligent materials in modern production Current trends for thermal shape memory alloys, 14th Global Congress on Manufacturing and Management (GCMM-2018), Procedia Manuf. 30, 347-356 (2019)

2. T. Takagi, J. Intell. Mater. Syst. Struct. 10, 575-581 (1999)

3. E. Hornbogen, M. Mertmann, Metall, 12/96, 809-814 (1996)

4. R. Frei, R. Mc William, B. Derrick, A. Purvis, A. Tiwari, G. Serugendo, Int. J. Adv. Manuf. Syst. 69, 1033-1061 (2013)

5. M. Rooij, K. Van Tittelboom, N. De Belie, E. Schlangen, (Springer, 2013)

6. M. Roig-Flores, S. Moscato, P. Serna, L. Ferrara, Constr. Build. Mater. 86, 1-11 (2015)

7. N. Z. Muhammad, A. Shafaghat, A. Keyvanfar, M. Z. Abd. Majid, S.K. Ghoshal, S.E.M. Yasouj, A. A. Ganiyu, M. S. Kouchaksaraei, H. Kamyab, M. M. Taheri, M. R. Shirdar, R. McCaffer, Constr. Build. Mater. 112, 1123-1132 (2016) 
8. A. Neville, Concr. Int. 24, 76-82, (2002)

9. L. Restuccia, A. Reggio, G. A. Ferroa, J. M. Tullianib, New self-healing techniques for cement-based materials, Procedia Struct. Integrity, 3, 253-260 (2017)

10. K. Van Tittelboom, N. De Belie, Materials 6(6), 2182-2217 (2013)

11. H. M. Jonkers, Bacteria-based self-healing concrete (HERON, 56, No. 1/2 2011)

12. A. Danish, M. A. Mosaberpanah, M. U. Salim, J. Mater. Res. Technol. 9, (to be published)

13. P. Termkhajornkit, T. Nawa, Y. Yamashiro, T. Saito, Cem. Concr. Compos. 31, 195-203 (2009)

14. L. Ferrara, V. Krelani, M. Carsana, Constr. Build. Mater. 68, 535-551 (2014)

15. T. H. Ahn, T. Kishi, J. Adv. Concr. Technol. 8, 171-186 (2010)

16. K. Van Tittelboom, E. Gruyaert, H. Rahier, N. De Belie, Constr Build Mater. 37, 349359 (2012)

17. S. H. Na, Y. Hama, M. Taniguchi, T. Sagawa, M. Zakaria, J. Adv. Concr. Technol. 10, 240-253 (2012)

18. S. Liu, M. Zuo, J. Adv. Mater. 306-307, 1020-1023 (2011)

19. H. Huang, G. Ye, D. Damidot, Cem. Concr. Res. 60, 68-82 (2014)

20. M. A. A. Sherir, K. M. A. Hossain, M. Lachemi, Constr. Build. Mater. 148, 789-810 (2017)

21. M. A. A. Sherir, K. M. A. Hossain, M. Lachemi, Constr. Build. Mater. 149, 164-185 (2017) 